\title{
Peran Karakteristik Responden dan Dukungan Tenaga Kesehatan dalam Identifikasi Faktor yang Terkait dengan Kegagalan Pemberian ASI Eksklusif
}

\author{
NurHamidah, Kuntoro \\ Departemen Biostatistika Dan Kependudukan FKM UNAIR \\ Fakultas Kesehatan Masyarakat Universitas Airlangga \\ Jl. Mulyorejo Kampus C Unair Surabaya 601115 \\ Alamat korespondensi: \\ Nur Hamidah \\ Email: hamidahalfie@gmail.com
}

\begin{abstract}
This study aims to identify the characteristics, factors support the role of health professionals and history place of birth of the respondents in the village Ngabab Pujon Malang. Type in this research was descriptive analytic study design. Samples from this study amounted to 72 respondents who have children aged 6-24 months was taken by simple random sampling, with a population of 144 respondents. Variables examined included the respondent characteristics such as age, education, and employment. While variable support role of health workers was a boosted in the form of exclusive breast-feed to the respondent when babies aged 0-6 months. For history variables place of birth that is the location where the respondent gave birth to her baby. The entire variable was measured using the enclosed questionnaire and analyzed using descriptive statistics. The result of this study is mostly mothers who are not exclusively breast-feeding are age 17-25 years which amounted to 35 (48.6\%). The last education taken by the respondent is junior that is numbered 35 (48.6\%). The majority of respondents worked, as many as 19 people (26.4\%) worked as a farmer. Analysis of factors which support 51 health workers (70.8\%) stated that health professionals do not support exclusive breast-feeding. For a history of childbed 36 people (50\%) maternity midwife. The conclusion of this research is that the majority of respondents aged 19-25 years, working as a farmer, the last junior high school education does not provide exclusive breast-feeding, health professionals do not support exclusive breast-feeding. Health workers are expected to provide education and action to support exclusive breastfeeding.
\end{abstract}

Keywords: failure of exclusive breastfeeding, health workers, place of birth

\begin{abstract}
ABSTRAK
Penelitian ini bertujuan untuk mengidentifikasi karakteristik, faktor peran dukungan tenaga kesehatan dan riwayat tempat bersalin responden di Desa Ngabab Kecamatan Pujon Kabupaten Malang. Jenis dalam penelitian ini adalah penelitian analitik dengan desain penelitian deskriptif. Sampel dari penelitian ini berjumlah 72 responden yang memiliki balita usia 6-24 bulan diambil dengan cara simple random sampling, dengan jumlah populasi sebesar 144 responden. Variabel yang diteliti meliputi karakteristik responden yaitu umur, pendidikan, dan pekerjaan. Sedangkan variabel peran dukungan tenaga kesehatan adalah bentuk dorongan dalam pemberian ASI secara eksklusif kepada responden saat bayinya berusia 0-6 bulan. Untuk variabel riwayat tempat bersalin yaitu lokasi tempat responden melahirkan bayinya. Seluruh variabel diukur menggunakan kuesioner tertutup dan dianalisis menggunakan descriptive statistics. Hasil dari penelitian ini adalah sebagian besar ibu balita yang tidak memberikan ASI eksklusif yaitu usia 17-25 tahun yaitu berjumlah 35 orang (48, 6\%). Pendidikan terakhir yang ditempuh oleh responden adalah SMP yaitu berjumlah 35 orang (48, 6\%). Mayoritas responden bekerja, yaitu sebanyak 19 orang $(26,4 \%)$ bekerja sebagai petani. Analisis dari faktor dukungan tenaga kesehatan yaitu 51 orang (70, $8 \%$ ) menyatakan tenaga kesehatan tidak mendukung pemberian ASI eksklusif. Untuk riwayat tempat bersalin 36 orang $(50 \%)$ bersalin di bidan. Kesimpulan pada penelitian ini adalah mayoritas responden berusia $17-25$ tahun, bekerja sebagai petani, berpendidikan terakhir SMP tidak memberikan ASI secara eksklusif, tenaga kesehatan tidak mendukung pemberian ASI eksklusif. Diharapkan tenaga kesehatan memberikan edukasi dan tindakan untuk mendukung pemberian ASI eksklusif.
\end{abstract}

Kata kunci: kegagalan ASI eksklusif, tenaga kesehatan, tempat bersalin 


\section{PENDAHULUAN}

Air Susu Ibu (ASI) merupakan makanan bayi baru lahir yang mengandung gizi paling baik sehingga dapat memenuhi semua nutrisi serta kebutuhan yang mana nantinya akan diperlukan untuk pertumbuhan serta berkembang hingga bayi berusia enam bulan (Depkes, 2008)

WHO menyarankan bahwa lebih baik hanya memberikan ASI eksklusif hingga bayi berusia enam bulan. Hasil kajian artikel yang telah dilakukan WHO menyatakan bahwa bayi yang telah mendapat ASI secara eksklusif selama enam bulan seringkali lebih sedikit menderita penyakit gastrointestinal atau gangguan pencernaan, dan lebih sedikit mengalami gangguan dalam pertumbuhan (World Health Organization, 2002).

ASI eksklusif adalah pemberian air susu ibu tanpa diberikan makanan maupun minuman tambahan lainnya pada bayi yang berumur nol sampai enam bulan. Hanya ASI saja yang dapat memenuhi kebutuhan gizi dan nutrisi bayi selama periode ini, tidak ada makanan dan minuman lain yang terbaik walaupun hanya air putih, air gula, pisang, yang kenyataannya tidak memiliki kandungan sebaik Air Susu Ibu (ASI) (Depkes, 2008).

Pemerintah telah mengeluarkan dan menetapkan kebijakan bahwa dalam rangka menurunkan angka kematian bayi yaitu melalui cara meningkatkan pemberian ASI eksklusif ketika bayi baru saja dilahirkan, hal ini telah diatur dalam Peraturan Pemerintah Nomor 33 Tahun 2012 yaitu mengenai pemberian Air Susu Ibu Secara eksklusif. Kematian yang terjadi pada balita dapat dikurangi hingga sebesar $13 \%$ melalui cara ibu menyusui bayinya secara eksklusif, lama menyusui yaitu enam bulan serta tetap memberikan ASI selama sebelas bulan dan diberikan makanan tambahan selain ASI setelah bayi berusia enam bulan (Roesli, 2008).

Di Indonesia pada saat ini dapat diketahui bahwa angka kematian bayi masih sangat tinggi yaitu 35/1.000 kelahiran hidup, yang memiliki arti bahwa dalam satu tahun sekitar 175.000 sebelum mencapai umur satu tahun bayi telah meninggal. Mengacu pada Survei Demografi Kesehatan Indonesia tahun 2002-2003, dapat diketahui bahwa dalam setiap satu jam kelahiran hanya ada empat persen bayi yang mendapat
ASI, dan hanya delapan persen bayi Indonesia yang mendapat ASI eksklusif hingga enam bulan (SDKI, 2012).

Berdasarkan data Survei Demografi dan Kesehatan Indonesia (SDKI), Angka Kematian Bayi (AKB) tahun 2007 sebesar 35 per 1.000 kelahiran hidup. Sedangkan menurut Badan Pusat Statistik (BPS) Provinsi Jawa Timur, AKB tahun 2009 sebesar 31, 41 per 1.000 kelahiran hidup tahun 2010 mencapai 29,99 per 1.000 kelahiran hidup, tahun 2011 mencapai 29, 24 per 1.000 kelahiran hidup dan di Tahun 2012 estimasi AKB mencapai 28, 31 per 1.000 kelahiran hidup (Dinkes, 2012).

Menurut data Kabupaten/kota diketahui bahwa cakupan bayi yang mendapatkan ASI eksklusif di Jawa Timur tahun 2012 yaitu sebesar $64,08 \%$. Cakupan tersebut walaupun mengalami peningkatan dibandingkan dengan tahun 2011 yaitu sebesar $61,52 \%$ akan tetapi angka ini masih kurang dari target pemerintah untuk ASI eksklusif sebesar $80 \%$. Hal ini sangat dipengaruhi oleh faktor pemahaman ASI eksklusif oleh pelaksana gizi di lapangan adalah murni bayi yang berusia sampai enam bulan yang mendapatkan ASI secara eksklusif (Dinkes, 2013).

Penolong persalinan sangat berpengaruh dalam pemberian ASI eksklusif, yaitu pada saat bayi pertama kali lahir maka IMD memiliki peluang lebih tinggi terhadap pelaksanaan pemberian ASI eksklusif hingga bayi berusia 6 bulan (Fikawati, 2009). Tenaga kesehatan juga memiliki peran penting dalam memberikan dorongan melalui informasi dalam bentuk tindakan. Pendidikan tinggi menandakan pengetahuan mengenai ASI eksklusif lebih baik daripada berpendidikan rendah. Hampir seluruh ibu melahirkan di sarana fasilitas kesehatan namun cakupan ASI eksklusif masih rendah (Putri, 2012).

Hasil survei ASI eksklusif di 17 Desa (4 Kecamatan) yaitu di kecamatan Singosari, Jabung, Ngantang dan kecamatan Pagelaran diperoleh bahwa cakupan ASI eksklusif sebesar 23, 53\% untuk mewakili cakupan ASI eksklusif di Kab. Malang, hal ini masih kurang dari target yang ditentukan oleh pemerintah yaitu sebesar $80 \%$. Sebanyak 34 Puskesmas tersebar di Kabupaten Malang. Untuk Kota Batu cakupan ASI eksklusif dengan rincian 3 kecamatan, 
dengan jumlah 5 puskesmas sebesar 56, 27\% jumlah ini juga masih kurang dari target yang ditentukan (Dinkes, 2014).

Berdasarkan studi pendahuluan yang telah dilakukan di Puskesmas Pujon data pemberian ASI saja pada umur 0-6 bulan Desa Ngabab Kecamatan Pujon Kabupaten Malang menempati urutan terendah dalam pencapaian pemberian ASI saja sampai berusia 6 bulan pada bulan Februari dan Agustus.

Jumlah bayi dan balita di Desa Ngabab yaitu sebanyak 157. Bayi dan balita yang tidak mendapatkan ASI secara eksklusif sebanyak 144 balita dan telah berusia 6-24 bulan yang artinya seluruh balita tersebut dulu nya tidak mendapatkan ASI secara eksklusif. Hal ini disampaikan oleh bidan Desa Ngabab bahwa sebagian besar bayi dan balita tidak mendapatkan ASI secara eksklusif.

\section{METODE PENELITIAN}

Penelitian yang dilakukan ini merupakan penelitian analitik dengan menggunakan desain penelitian deskriptif. Lokasi pada penelitian ini yaitu berada di Desa Ngabab Kecamatan Pujon Kabupaten Malang. Waktu penelitian ini dilaksanakan pada bulan Desember tepatnya mengikuti 4 pos pada posyandu balita yaitu pada tanggal 2, 4, 6, dan 8 Desember pada tahun 2015. Populasi yang ada dalam penelitian ini adalah seluruh ibu balita yang memiliki balita berusia 6-24 bulan yang gagal dalam memberikan ASI secara eksklusif.

Pengambilan sampel yang dilakukan dalam penelitian ini yaitu menggunakan simple random sampling. Jumlah sampel yang digunakan dalam penelitian yaitu sebanyak 72 ibu yang memiliki balita usia 6-24 bulan dan mengalami kegagalan dalam memberikan ASI secara eksklusif. Variabel yang diteliti yaitu karakteristik responden terdiri dari usia, pendidikan, dan pekerjaan.

Sedangkan variabel dukungan tenaga kesehatan yang diteliti adalah seberapa besar dukungan atau dorongan mengenai ASI eksklusif dari tenaga kesehatan. Untuk tempat bersalin yang diteliti adalah di mana tempat mayoritas ibu bersalin. Seluruh variabel dalam penelitian ini akan diukur menggunakan kuesioner tertutup dan dianalisis dengan deskriptif statistik.

\section{HASIL PENELITIAN}

\section{Gambaran Umum Daerah Penelitian}

Berdasarkan data Administrasi Pemerintah Desa Tahun 2014 menyebutkan bahwa Desa Ngabab merupakan salah satu Desa yang letaknya berada di Kecamatan Pujon, Kabupaten Malang, Provinsi Jawa Timur. Dilihat dari segi topografi, Desa Ngabab berada di dataran tinggi dan terdapat banyak sekali bukit, Desa Ngabab memiliki ketinggian $1200 \mathrm{~m}$ di atas permukaan laut dengan kisaran suhu antara 8-18 ${ }^{\circ} \mathrm{C}$, curah hujan 2, 3 sampai $2400 \mathrm{~mm} / \mathrm{th}$. Desa Ngabab dilewati jalur utama lalu lintas darat yang menghubungkan antara kota Kediri dan kota Malang. Desa Ngabab berbatasan langsung dengan;

Sebelah barat: Desa Tulungrejo

Sebelah selatan: Desa Sukomulyo

Sebelah utara: Desa Tawang Sari

Sebelah timur: Desa Ngroto

Jumlah penduduk yang ada di Desa Ngabab adalah berjumlah 7412 orang dengan rincian 3677 orang berjenis kelamin perempuan dan 3735 orang berjenis kelamin laki-laki.

Tabel 1. Usia dan Pendidikan Responden

\begin{tabular}{lcccc}
\hline \multirow{2}{*}{ Pendidikan } & \multicolumn{3}{c}{ Usia } & \multirow{2}{*}{ Total } \\
\cline { 2 - 4 } & $\mathbf{1 7 - 2 5}$ & $\mathbf{2 6 - 3 5}$ & $\mathbf{3 6 - 4 5}$ & \\
\hline SD & $2(12,5 \%)$ & $7(43,8 \%)$ & $7(43,8 \%)$ & $16(22,2 \%)$ \\
SMP & $22(62,9 \%)$ & $9(25,7 \%)$ & $4(11,4 \%)$ & $35(48,6 \%)$ \\
SMU & $9(52,9 \%)$ & $6(35,3 \%)$ & $2(11,8 \%)$ & $17(23,6 \%)$ \\
PT & $2(50 \%)$ & $1(25 \%)$ & $1(25 \%)$ & $4(5,6 \%)$ \\
\hline Total & $\mathbf{3 5 ( 4 8 , 6 \% )}$ & $\mathbf{2 3 ( 3 1 , 9 \% )}$ & $\mathbf{1 4}(\mathbf{1 9 , 4 \% )}$ & $\mathbf{7 2}(\mathbf{1 0 0 \% )}$ \\
\hline
\end{tabular}




\section{Karakteristik Responden}

\section{Usia dan Pendidikan}

Berdasarkan tabel 1 dapat diketahui bahwa Ibu dengan dari 35 orang yang pendidikan terakhir nya SMP sebagian besar usia 17-25 tahun.

Berdasarkan tabel 1 dapat diketahui bahwa pendidikan terakhir ibu balita mayoritas adalah SMP, yaitu sebanyak 35 orang $(48,6 \%)$.

Dapat disimpulkan bahwa ibu responden yang paling banyak yaitu berusia 17-25 tahun. Usia ini masuk dalam kategori usia remaja akhir (Depkes, 2009), dan pendidikan terakhir ibu terbanyak adalah sampai SMP yaitu 35 orang (48,6\%). Usia menikah serta pendidikan ibu perlu mendapatkan sorotan karena dengan umur yang relatif muda ini ibu balita dituntut paham dan mengerti akan manfaat ASI eksklusif. Perlu pendekatan intensif dan berkala untuk memberikan pengertian mendalam mengenai ASI.

\section{Pekerjaan}

Kegiatan aktif yang sering dilakukan responden dalam melakukan tugas pokok sehari-hari dan menghasilkan penghasilan untuk mencukupi kehidupannya.

Berdasarkan tabel 2 dapat diketahui bahwa mayoritas responden di Desa Ngabab bekerja. Pekerjaan yang paling banyak yaitu sebagai petani sebesar 19 orang (26,4\%). Dapat disimpulkan bahwa ibu yang bekerja sebagai petani tidak menyusui bayinya secara eksklusif.

Telah disebutkan bahwa sektor pertanian dan peternakan merupakan jantung dari Desa Pujon.

Tabel 2. Pekerjaan Responden

\begin{tabular}{lcc}
\hline Pekerjaan & $\begin{array}{c}\text { Jumlah } \\
\text { (n) }\end{array}$ & $\begin{array}{c}\text { Persentase } \\
(\mathbf{\%})\end{array}$ \\
\hline Pegawai Swasta & 7 & 9,7 \\
Wiraswasta & 12 & 16,7 \\
Peternak Sapi & 10 & 13,9 \\
Petani & 19 & 26,4 \\
Buruh Tani & 2 & 2,8 \\
Tidak Bekerja & 22 & 30,6 \\
\hline Total & $\mathbf{7 2}$ & $\mathbf{1 0 0}$ \\
\hline
\end{tabular}

Tabel 3. Tenaga Kesehatan Mengingatkan Jika Asi Eksklusif Sangat Penting Diberikan

\begin{tabular}{lcc}
\hline & $\begin{array}{c}\text { Jumlah } \\
\text { (n) }\end{array}$ & $\begin{array}{c}\text { Persentase } \\
(\%)\end{array}$ \\
\hline Tidak pernah & 9 & 12,5 \\
Kadang-kadang & 34 & 47,2 \\
Sering & 24 & 33,3 \\
Selalu & 5 & 6,9 \\
\hline Total & $\mathbf{7 2}$ & $\mathbf{1 0 0}$ \\
\hline
\end{tabular}

Tabel 4. Petugas Kesehatan Menyarankan Susu Formula Karena ASI Kurang Setelah Bersalin

\begin{tabular}{lcc}
\hline & $\begin{array}{c}\text { Jumlah } \\
\text { (n) }\end{array}$ & $\begin{array}{c}\text { Persentase } \\
(\mathbf{\%})\end{array}$ \\
\hline Selalu & 43 & 59,7 \\
Sering & 24 & 33,3 \\
Kadang-kadang & 5 & 6,9 \\
\hline Total & $\mathbf{7 2}$ & $\mathbf{1 0 0}$ \\
\hline
\end{tabular}

Meskipun 22 orang lainnya tidak bekerja, dari hasil wawancara singkat didapatkan bahwa ibuibu tersebut memiliki kebiasaan membantu suami mereka memberi minum dan makanan kepada ternak mereka.

\section{Tenaga Kesehatan Mengingatkan Pentingnya} ASI

Tenaga kesehatan memiliki peran yang penting dalam meningkatkan keberhasilan ASI.

Dari tabel 3 dapat diketahui bahwa tenaga kesehatan kadang-kadang mengingatkan jika ASI eksklusif penting diberikan yaitu sebesar 34 orang $(47,2 \%)$ yang menyatakan hal tersebut.

\section{Tenaga Kesehatan Menyarankan Susu Formula}

Promosi susu formula dapat berasal dari media massa, elektronik, dan bahkan melalui tenaga kesehatan.

Dari tabel diatas dapat diketahui bahwa sebagian besar yaitu 43 orang $(59,7 \%)$ responden menyatakan bahwa tenaga kesehatan selalu 
Tabel 5. Analisis Dukungan

\begin{tabular}{lcc}
\hline & $\begin{array}{c}\text { Jumlah } \\
\text { (n) }\end{array}$ & $\begin{array}{c}\text { Persentase } \\
(\mathbf{\%})\end{array}$ \\
\hline Mendukung & 21 & 29,2 \\
Tidak mendukung & 51 & 70,8 \\
\hline Total & $\mathbf{7 2}$ & $\mathbf{1 0 0}$ \\
\hline
\end{tabular}

Tabel 6. Distribusi Riwayat Tempat Bersalin

\begin{tabular}{lcc}
\hline Status & $\begin{array}{c}\text { Jumlah } \\
\text { (n) }\end{array}$ & $\begin{array}{c}\text { Persentase } \\
(\%)\end{array}$ \\
\hline Rumah sakit umum/ & 26 & 36,1 \\
swasta & & 50,0 \\
Bidan & 36 & 8,3 \\
Poskesdes & 6 & 5,6 \\
Puskesmas & 4 & $\mathbf{1 0 0}$ \\
\hline Total & $\mathbf{7 2}$ & \\
\hline
\end{tabular}

menyarankan susu formula karena ASI kurang setelah bersalin.

Ibu balita diharapkan mengerti akan hak nya sebagai pasien yaitu berhak menyusui bayinya dan mengetahui bahwa bayi memiliki juga memiliki hak untuk mendapatkan ASI eksklusif.

\section{Analisis Dukungan Tenaga Kesehatan}

Dari tabel 5 dapat disimpulkan bahwa sebesar 51 orang $(70,8 \%)$ menyatakan bahwa tenaga kesehatan tidak mendukung dalam pemberian ASI eksklusif. Hasil analisis ini dikuatkan dengan tabel 4 . yang menyebutkan bahwa tenaga kesehatan menyarankan susu formula karena ASI kurang setelah bersalin.

\section{Tempat Bersalin}

Tempat bersalin merupakan kunci pertama untuk dapat melakukan IMD sehingga ASI eksklusif dapat diberikan setelahnya.

Dari tabel diatas dapat diketahui bahwa mayoritas responden yaitu sebesar 36 orang (36, $1 \%$ ) bersalin di bidan.

\section{PEMBAHASAN}

\section{Usia}

Berdasarkan hasil penelitian yang telah dilakukan, didapatkan bahwa sebagian besar ibu balita yaitu berusia 17-25 tahun. Pada penelitian yang dilakukan sebelumnya menyebutkan bahwa Ibu yang lebih tua dan memiliki paritas tinggi dapat menyusui bayinya secara eksklusif (Fikawati, 2009).

Ibu adalah kunci serta tolok ukur dari kesuksesan pemberian ASI secara eksklusif. Melihat umur ibu yang masih muda perlu adanya edukasi mengenai ASI. Tidak hanya sekedar tahu apa itu ASI melainkan harus diisi dengan pemahaman yang mendalam mengenai manfaat pemberian ASI beserta kandungan gizinya. Hal ini bertujuan agar ibu muda yang telah memiliki bayi mampu serta siap dalam memberikan ASI secara eksklusif kepada bayinya.

Pengalaman selama menyusui memiliki peran yang penting. Pengalaman yaitu sumber pengetahuan informal yang pemanfaatannya dapat ditentukan dengan cara seseorang merefleksikannya kembali. Hal ini terkait dengan ibu yang masih muda perlu meningkatkan pengalaman untuk lebih mengetahui dan memberikan ASI secara eksklusif. Apabila pada usia muda ibu telah mengerti dan paham dalam menghadapi masalah menyusui maka pada kehamilan berikutnya ibu sudah tidak kaku lagi dan kebingungan menghadapi masalah ASI. Hal ini berlaku jika ibu menyalurkan pengetahuan dan ilmu yang mendalam ini kepada putrinya kelak serta saudara dan orang terdekatnya.

Berdasarkan analisis hubungan yang terdapat pada sebuah penelitian menyebutkan bahwa ada hubungan yang bermakna antara umur dengan pemberian ASI eksklusif. Hal ini dapat terjadi karena ada pengaruh dari faktor lain misalnya faktor penghasilan, ataupun nasehat selama ibu hamil dan saat menyusui (Sriningsih, 2011).

\section{Pekerjaan}

Sebagian besar ibu yang bekerja tidak menyusui bayinya secara eksklusif. Pekerjaan yang banyak dilakukan ibu balita adalah sebagai petani.

Menurut survei di DKI Jakarta, diketahui bahwa tingkat pemberian ASI secara eksklusif yaitu terdapat di kalangan ibu tidak bekerja sebesar $14 \%$. Pada ibu yang bekerja, tingkat pemberian ASI secara eksklusif menurun tajam yaitu mencapai $1,4 \%$. Hal ini bisa disebabkan oleh terpisahnya ibu dan bayi sehingga Ibu tidak 
dapat sewaktu-waktu memberikan ASI pada bayinya (Februhartanty, 2012).

Penelitian yang dilakukan oleh Merdeyanti (2007) dengan hasil bahwa proporsi ibu yang tidak patuh memberikan ASI eksklusif pada ibu yang bekerja adalah $60 \%$, dengan risiko 1, 5 kali lebih besar dibandingkan dengan ibu yang tidak bekerja. Penelitian yang dilakukan oleh Petit (2008) menunjukkan bahwa terdapat $37,9 \%$ wanita yang tidak menyusui bayinya secara eksklusif. Mayoritas (50\%) bahwa ASI mereka tidak mencukupi untuk bayinya, 24, 6\% dikarenakan bayi gagal untuk menyusui dan hanya $19.4 \%$ mengatakan karena alasan ibu bekerja.

Ibu yang tidak bekerja dapat menyusui bayinya secara eksklusif karena waktu luang yang diberikan untuk bayinya lebih banyak, hal tersebut perlu diimbangi dengan pengetahuan yang lebih baik agar keberhasilan menyusui tercapai (Rebhan, 2009).

Apapun pekerjaan yang ibu jalani apabila pemahaman ibu mengenai ASI eksklusif baik, maka keberhasilan pemberian ASI dapat terlaksana dengan baik pula.

Desa Ngabab merupakan desa Agrobisnis. Pertanian dan peternakan di Desa Ngabab memiliki peran penting, dari hasil pertanian dan peternakan diharapkan dapat meningkatkan perekonomian penduduknya. Sehingga kebutuhan sehari-hari dapat terpenuhi. Banyaknya ibu yang gagal dalam pemberian ASI eksklusif perlu mendapatkan perhatian. Ibu bisa saja mempercayakan orang lain untuk sementara mengerjakan lahan pertaniannya sehingga ibu bisa fokus menyusui bayinya. Apabila tidak bisa melakukannya maka ibu dapat memerah ASI nya serta menaruh dalam freezer untuk sewaktuwaktu diberikan kepada sang bayi. Hal yang sama juga dapat dilakukan apabila Ibu memiliki pekerjaan selain petani.

\section{Pendidikan}

Sebagian besar penduduk Desa Ngabab pendidikan terakhirnya adalah SMP. Pada sebuah penelitian Sandra (2009), disebutkan bahwa jika ibu balita yang memiliki pendidikan tinggi maka pengetahuan yang dimiliki ibu juga akan tinggi, begitu pula sebaliknya. Hal tersebut juga berdampak pada perilaku ibu balita. Ibu yang memiliki pengetahuan yang sangat baik mengenai ASI eksklusif maka akan cenderung meminta tenaga kesehatan agar tidak memberikan susu formula maupun makanan dan minuman tambahan lain pada bayinya. Ibu balita diharapkan tidak segan dan meminta bayinya untuk diberikan kolostrum sehingga pemberian ASI eksklusif dapat berjalan dengan baik. Pendidikan yang tinggi juga dapat memberikan kepercayaan tinggi untuk sanggup mengutarakan keinginan dan pemikirannya. Pengetahuan yang luas memungkinkan ibu untuk dapat menambahkan atau memperbaharui pengetahuan yang ada. Sehingga ibu dapat terbuka dan dengan senang hati menerima informasi baru yang akan diberikan selama informasi tersebut beralasan kuat dan berdasarkan kenyataan dengan fondasi kuat (Fikawati, 2009).

Ibu yang memiliki pengetahuan tinggi maka dapat mengetahui hak dirinya dan hak bayinya untuk mendapatkan ASI secara eksklusif. Ibu dapat menolak apabila tenaga kesehatan menawarkan susu formula atau bahkan minuman lain kecuali vitamin dan obat kepada responden.

Berbeda dengan penelitian yang dilakukan Nuriha (2014), di BPS tahun 2007 yang menyebutkan bahwa $56 \%$ dari ibu yang pendidikan formalnya rendah secara konsisten dapat menyusui bayinya secara berkala, sehingga peluang bayi mendapatkan ASI eksklusif lebih besar. Sedangkan untuk Ibu yang pendidikan terakhirnya SMA atau universitas hanya 40 , $2 \%$ saja yang memberikan ASI secara eksklusif (Abdul, 2014)

\section{Dukungan Tenaga Kesahatan}

Hasil analisis dukungan tenaga kesehatan mengenai pemberian ASI eksklusif di Desa Ngabab yaitu 51 orang $(70,8 \%)$ menyatakan bahwa tenaga kesehatan tidak mendukung dalam pemberian ASI eksklusif.

Keadaan di mana Ibu pertama kali mengalami persalinan dan menyusui kontak pertamanya adalah dengan penolong persalinan, yaitu tenaga kesehatan. Tenaga kesehatan juga memiliki peran yang sangat penting dalam mewujudkan keberhasilan pemberian ASI eksklusif, atau bahkan penyebab terjadinya kegagalan dalam pemberian ASI secara eksklusif. Apabila tidak memungkinkan ibu dan bayi berada 
dalam satu ruangan yang sama akan tetapi tenaga kesehatan dan ibu menyadari dan memahami betapa pentingnya ASI eksklusif maka rawat pisah bukan menjadi masalah yang serius untuk terus menyusui secara berkala.

Ketidaktahuan ibu mengenai tanda saat bayi lapar dan pentingnya pemenuhan gizi melalui ASI eksklusif membuat kondisi ibu menyetujui untuk memberikan susu formula karena tenaga kesehatan juga menyediakan susu formula sebagai tambahan apabila ibu balita memiliki masalah yaitu ketika air susu masih belum keluar, atau sudah keluar tetapi sedikit sehingga ibu merasa ASI nya tidak cukup untuk diberikan.

Kurangnya dukungan dari tenaga kesehatan menyebabkan gagalnya pemberian ASI eksklusif. Tidak hanya pemberian informasi dan edukasi mengenai ASI saja yang dapat disampaikan oleh tenaga kesehatan melainkan dengan bentuk tindakan yang nyata, yaitu dengan cara tidak memberikan bantuan susu apapun tanpa adanya indikasi tertentu. Pemberian susu formula pada bayi harus berdasarkan dengan indikasi medis. Susu formula dapat diberikan ketika bayi hanya mampu menerima susu dengan susu formula khusus. Sedangkan kondisi lain yang memperbolehkan bayi mengonsumsi susu formula yaitu bayi yang membutuhkan makanan lain selain ASI dalam waktu yang terbatas. Kondisi medis ibu yang tidak dapat memberikan ASI nya karena harus mendapatkan pengobatan khusus, keadaan di mana ibu dengan kondisi HbsAg (+), dan bayi belum diberikan vaksinasi hepatitis yang aktif dan pasif dalam 12 jam juga merupakan syarat yang diperbolehkan menggunakan susu formula (Permenkes, 2013).

Pada studi sebuah penelitian yang dilakukan Sandra dan Ahmad (2009), menyebutkan bahwa tenaga kesehatan melaksanakan prosedur pemberian ASI eksklusif. Prosedur tersebut terdapat kesulitan diantaranya yaitu harus selalu rajin terus menerus mendekatkan bayi kepada ibunya, selalu sabar dalam memantau kondisi bayi apabila bayi menangis terus menerus. Tidak terburu - buru mengambil bayi dari dada ibu. Ketika dilakukan IMD tenaga kesehatan biasanya hanya memberikan waktu pada bayi 30 menit berada di dada ibu dan distributor susu formula memberikan hadiah yang menguntungkan bagi tenaga kesehatan sehingga tenaga kesehatan tertarik mengadakan kontrak susu formula (Fikawati, 2009).

Dari penelitian yang dilakukan Kriselly pada tahun 2012 menyebutkan bahwa dukungan dari petugas kesehatan masih sangat kurang, terbukti bahwa responden lebih sering berdiskusi dengan keluarga mereka untuk masalah pemberian ASI secara eksklusif ini, sedangkan informasi mengenai pemberian ASI eksklusif masih kurang dari tenaga kesehatan. Petugas kesehatan seharusnya menjadi panutan tempat penyelesaian masalah kesehatan termasuk masalah dalam menyusui secara eksklusif (Yarina, 2012).

Petugas kesehatan menjadi acuan bagi perilaku kesehatan masyarakat. Agar masyarakat memiliki perilaku yang baik dan benar mengenai pandangan kesehatan dan pemberian ASI eksklusif maka tenaga kesehatan perlu meningkatkan dukungan, serta tidak menyarankan mengonsumsi susu formula tanpa ada indikasi medis tertentu.

Masa kehamilan adalah waktu yang paling penting untuk persiapan ibu dalam menyusui secara eksklusif. Pada saat ibu melalukan ANC maka tenaga kesehatan bisa memulai melakukan intervensi untuk memberikan informasi dan edukasi mengenai pentingnya ASI eksklusif. Tenaga kesehatan juga memberikan solusi mengenai masalah yang mungkin akan dihadapi ibu kelak ketika menyusui, agar ibu dapat mempersiapkan diri untuk menyusui secara eksklusif kelak. Hendaknya tenaga kesehatan tidak bicara secara menggurui atau memaksa ibu balita dalam memberikan penjelasan mengenai ASI eksklusif, biarkan ibu bicara dan beri kesempatan untuk bertanya atas ketidaktahuannya mengenai ASI eksklusif.

Persiapan dalam pemberian ASI secara eksklusif tidak bisa dilakukan secara instan dan singkat. Perlu tahapan dan proses yang mendalam agar pemberian susu formula dan minuman lain dapat dihindari saat bayi baru lahir. Kemungkinan bayi mendapatkan susu formula walau hanya sesendok dan madu mungkin sekali dapat terjadi.

Dari hasil penelitian yang telah dilakukan yaitu mengenai perawatan payudara, sebagian responden menyatakan bahwa kadang - kadang tenaga kesehatan memberitahu cara perawatan payudara dengan baik. Tindakan ini sangat 
penting dilakukan untuk persiapan ibu menyusui kelak. Hendaknya tenaga kesehatan secara rutin mengingatkan dan mengedukasi mengenai perawatan payudara, membuka kelas perawatan payudara dan membuka konsultasi mengenai masalah ASI saat posyandu. Tenaga kesehatan juga perlu menyampaikan informasi yang benar mengenai mitos yang sering beredar dan kebenarannya masih belum jelas.

Dari hasil penelitian menyatakan bahwa tenaga kesehatan selalu mengingatkan untuk menyusui serta menjelaskan bahwa ASI eksklusif sangat penting diberikan. Kenyataannya tenaga kesehatan juga menyarankan memberi susu formula saat ibu bayi memiliki masalah yang dihadapi ketika menyusui. Dalam hal ini ketegasan dan solusi lain perlu tenaga kesehatan kembangkan.

\section{Riwayat Tempat Bersalin}

Dari hasil penelitian disebutkan bahwa mayoritas ibu melahirkan bayinya di bidan. Tempat pertama kali ibu melahirkan memiliki peran yang sangat penting, karena keberhasilan ASI eksklusif bergantung pada masa awal kelahiran bayi.

Seluruh ibu menggunakan fasilitas kesehatan seperti rumah sakit, bidan, puskesmas, dan poskesdes. Penolong persalinan ibu bayi yaitu tenaga kesehatan.

Rendahnya cakupan ASI eksklusif dapat diketahui karena petugas kesehatan dalam hal ini bidan masih kurang dalam memberikan dukungan terhadap keberhasilan ASI eksklusif.

Sebenarnya kegagalan pemberian ASI eksklusif bukan hanya semata-mata dikarenakan kelalaian tenaga kesehatan saja akan tetapi meningkatnya promosi pengganti ASI sering menggoyahkan keyakinan ibu dan tenaga kesehatan yaitu bidan. Maraknya iklan promosi susu formula di sosial media dan sarana komunikasi yang semakin maju menambah sulitnya pemberian ASI secara eksklusif (Roesli, 2000).

Dari hasil penelitian menyatakan bahwa tempat bersalin memiliki hubungan yang signifikan dengan keberhasilan menyusui (Dewi, 2010).
Dalam hal ini perlu dukungan bidan dan sikap tegas tenaga kesehatan di tempat bersalin untuk memberikan penjelasan dan informasi secara berkala dan mendalam kepada ibu balita saat posyandu serta peran bidan dalam membina para kader untuk selalu mengingatkan ibu untuk selalu menyusui secara eksklusif. Kebijakan yang diterapkan dalam lingkungan kerja di tempat bersalin untuk menerapkan pemberian ASI secara eksklusif perlu diterapkan dan ditaati oleh seluruh tenaga kesehatan

\section{SIMPULAN DAN SARAN}

\section{Simpulan}

Karakteristik responden meliputi umur, pendidikan, dan pekerjaan dari penelitian ini dapat disimpulkan bahwa ibu balita yang memiliki umur 17-25 tahun tidak menyusui secara eksklusif. ibu yang pendidikan terakhirnya SMP dan bekerja sebagai petani tidak menyusui secara eksklusif. Dukungan tenaga kesehatan mayoritas Ibu balita menyatakan bahwa tenaga kesehatan tidak mendukung dalam pemberian ASI secara eksklusif. Untuk riwayat tempat ibu bersalin dapat disimpulkan bahwa mayoritas ibu balita melahirkan di tempat tenaga kesehatan yaitu bidan.

\section{Saran}

Untuk meningkatkan jumlah pemberian ASI eksklusif maka dari itu diperlukan adanya usaha dalam meningkatkan informasi mengenai ASI selama sebelum kehamilan, saat hamil dan awal menyusui bayi secara bertahap serta mendalam mengenai ASI eksklusif agar ibu balita mudah memahami dan mengerti arti bagaimana menyusui secara eksklusif itu sebenarnya. Diharapkan untuk seluruh tenaga kesehatan terutama bidan agar lebih tegas lagi serta cerdas dalam membina kesejahteraan ibu balita mengenai menyusui bayi secara eksklusif. Tenaga kesehatan diharapkan tidak menyarankan untuk memberikan susu formula tanpa indikasi yang berarti. Diharapkan tempat layanan kesehatan lebih memperhatikan lagi dalam hal meningkatkan promosi pemberian 
ASI eksklusif dengan menyebar selebaran, brosur akan pentingnya ASI eksklusif serta mengadakan pelatihan ASI secara berkala sebagai bekal ilmu untuk tenaga kesehatan nantinya dalam membina serta meningkatkan jumlah ibu yang menyusui secara eksklusif.

Kebijakan juga diperlukan demi tercipta tujuan utama dalam pencapaian target dalam menyusui secara eksklusif, terutama mengenai peredaran susu formula yang notabene sudah menjadi hal yang biasa beredar di lingkungan tenaga kesehatan. Perlu adanya kebijakan yang tegas dari pemerintah daerah maupun pemerintah pusat.

\section{DAFTAR PUSTAKA}

Depkes. 2008.Modul Kegiatan Inisiasi Menyusui Dini (IMD) dan ASI Eksklusif 6 Bulan.Jakarta: Departemen Kesehatan.

Dewi, R. 2010. Pengaruh Post Partum Blues Terhadap Keberhasilan Menyusui di Kota Bengkulu Propinsi Bengkulu. Media Kesehatan, 13.

Dinkes. 2014. Profil Kesehatan Kabupaten Malang. Malang: Dinas Kesehatan Kab. Malang.

Dinkes. 2012. Profil kesehatan provinsi Jawa Timur. Surabaya: Dinas Kesehatan provinsi.

Dinkes. 2013. Profil kesehatan provinsi Jawa Timur. Surabaya: Dinas Kesehatan.

Abdul, N. 2014. Menelusuri Akar Masalah Rendahnya Persentase Pemberian ASI Eksklusif di Indonesia. Al Hikmah Vol.XV Nomor 1/2014, 110.

Februhartanty., 2012. Profiles of Eight Working Mothers Who Practiced Exclusive. Breastfeeding medicine, 54.
Hamidah, N. 2016. Identifikasi Faktor yang terkait dengan Kegagalan dalam Pemberian ASI eksklusif Pada Bayi $0=6$ Bulan. skripsi: Universitas Airlangga. Surabaya

Permenkes. 2013. Pekan ASI Sedunia Permenkes Nomor 39 Tahun 2013. Jakarta: Direktorat Bina Gizi.

Putri, P. 2012. Gambaran Faktor-Faktor yang Memengaruhi Pemberian ASI eksklusif di Kelurahan Kunciran Indah Tangerang: Universitas Indonesia, Surabaya 47-48.

Rebhan, B. K. 2009. Breastfeeding Duration and Exclusivity. Data From a Prospective Cohort Study in Bavaria, Germany. Acta Pcediatrica, , 974-980.

Roesli, U. 2008. Inisiasi menyusu dini plus ASI eksklusif. Jakarta: Pustaka Bunda.

Roesli, U. 2000. Mengenal ASI Eksklusif. Jakarta: Trubus Agriwidya.

SandraFikawati,A.S. 2009.Penyebab Keberhasilan dan kegagalan Praktik Pemberian ASI Eksklusif. Kesehatan Masyarakat Nasional vol. 4 No. 3, 130.

SDKI. 2012. Survei Demografi dan Kesehatan Indonesia. Jakarta: Badan Pusat Statistik.

Sriningsih, I. 2011. Faktor Demografi, Pengetahuan Ibu Tentang Air Susu Ibu dan Pemberian ASI Eksklusif. Kesehatan Masyarakat, 104.

World Health Organization. 2002. The Optimal Duration of Exclusive Breastfeeding. Geneva Switzerland: Report of an Expert Consultation

Yarina, K. 2012. Studi Kualitatif Terhadap rendahnya Cakupan ASI Eksklusif. Kesehatan Masyarakat, 71-72. 